\begin{tabular}{|c|c|c|c|c|c|c|c|c|c|c|}
\hline Case & Sex & $\begin{array}{c}\text { Age } \\
\text { (years) }\end{array}$ & $\begin{array}{c}\text { Duration of RA } \\
\text { (months) }\end{array}$ & $\begin{array}{l}\text { RF } \\
+/-\end{array}$ & $\begin{array}{c}\text { APCA } \\
+/- \\
\end{array}$ & $\begin{array}{c}\text { Erosive } \\
\text { RA }\end{array}$ & HZ Localization & $\begin{array}{c}\text { Previous Herpes Viral } \\
\text { serology }\end{array}$ & $\begin{array}{c}\mathrm{HZ} \\
\text { Treatment } \\
\end{array}$ & $\begin{array}{c}\text { Concomitant treatment for } \\
\text { RA }\end{array}$ \\
\hline 1 & 운다 & 74 & 339 & + & + & Yes & Left arm & $\lg G+\lg M N R$ & Famciclovir & Corticoids/MTX/TCZ \\
\hline 2 & ㅇ & 86 & 142 & + & - & Yes & - & $\lg G+\lg M-$ & None (topic) & ETN \\
\hline 3 & 우 & 80 & 90 & - & - & Yes & Gluteus (right) & $\lg G+\lg M N R$ & Brivudina & $\mathrm{HCQ}$ \\
\hline 4 & ㅇ & 83 & 313 & + & - & Yes & $\begin{array}{l}\text { D9-D10 } \\
\text { metamer }\end{array}$ & $\lg G+\lg M-$ & Brivudina & Corticoids/MTX/RTX \\
\hline 5 & 운 & 52 & 222 & + & - & Yes & Generalizated & $\lg G+\lg M N R$ & Aciclovir & Corticoids \\
\hline 6 & ㅇ & 70 & 171 & + & - & No & Left arm & $\lg G+\lg M N R$ & Aciclovir & Corticoids/MTX/ADA \\
\hline 7 & ㅇ & 68 & 1 & + & - & Yes & Intercostal (left) & $\lg G+\lg M-$ & Brivudina & Corticoids/HCQ \\
\hline 8 & + & 61 & 40 & - & - & No & - & $\lg G+\lg M N R$ & - & Corticoids/LFN/TCZ \\
\hline 9 & $\sigma^{x}$ & 58 & 34 & + & + & No & Intercostal (left) & $\lg G+\lg M N R$ & Famciclovir & None \\
\hline 10 & ㅇ & 62 & 67 & + & + & Yes & Intercostal (left) & $\lg G+\lg M N R$ & Aciclovir & LFN/ETN \\
\hline 11 & ㅇ & 50 & 5 & - & - & No & Intercostal (left) & $\lg G+\lg M N R$ & Aciclovir & Corticoids/MTX/ADA \\
\hline 12 & ㅇ & 66 & 2 & + & + & No & Gluteus (left) & $\lg G+\lg M-$ & Aciclovir & None \\
\hline
\end{tabular}

TABLE General features of 12 RA patients at $\mathrm{HZ}$ infection

drugs, are involve in this increased risk. Furthermore, in these patients is more frequent a disseminated presentation of zoster involving several dermatomes.

Objectives: In a series of RA patients our aim was analyzed $\mathrm{HZ}$ infections and to assess a) $\mathrm{HZ}$ prevalence and b) $\mathrm{HZ}$ general features

Methods: Prospective Single center study of 390 RA patients included in the vaccination program of the Preventive and Rheumatology department of our hospital between october 2011 and october 2016. The follow-up was made until December 2017. HZ vaccination is not included in our program.

RA was diagnosed according to the ACR/EULAR 2010 proposed criteria (Arthritis Rheum 2010; 62: 2569-2581)

The diagnose of $\mathrm{HZ}$ was made according to the clinical manifestations and was confirmed by a dermatologist. These manifestations were characteristic skin rash and blisters, paresthesia and local pain, in one (localized) or more dermatomes (generalized)

Results: We studied 390 patients $\left(307 \% / 830^{x}\right)$, average age $61.28 \pm 12.9$ years that were included in the vaccination program and followed-up. $\mathrm{HZ}$ infection was observed in 12 of 390 (3.07\%) in the follow-up (TABLE).

The 12 RA patients (11 women/1 man) with a mean $\pm S D$ age of 67.5 \pm 11.67 . More than half of patients, 7 (58.33\%) were taking corticosteroids. 8 patients $(66.66 \%)$ were receiving conventional disease modifying drugs (DMARDs) methotrexate (33.33\%), leflunomide (16.66\%) and hydroxychloroquine (16.66\%). Besides corticosteroids and conventional DMARDs, 7 patients $(58.33 \%)$ were in treatment with biologic drugs, tocilizumab $(n=2)$, etanercept $(n=2)$, adalimumab $(n=2)$, and rituximab $(n=1)$. Conclusion: Herpes zoster is a relative frequent viral infection in RA patients non-vaccine for $\mathrm{HZ}$. The female sex, older age, more aggressive RA and treatment with corticosteroids were more frequent. Probably in this group of patients $\mathrm{HZ}$ vaccination may be useful.

Abbreviatures: MTX: methotrexate, LFN: leflunomide, HCQ: hydroxicloroquine, TCZ: tocilizumbas, ADA: adalimumab, ETN: etanercept

Disclosure of Interests: Lucia Domínguez: None declared, Vanesa CalvoRío: None declared, Paz Rodriguez-Cundin: None declared, Virginia Portilla: None declared, Nuria Vegas-Revenga: None declared, Francisco Manuel Antolin-Juarez: None declared, Maria Henar Rebollo Rodriguez: None declared, Alfonso Corrales: None declared, D. Prieto-Peña: None declared, Monica Calderón-Goercke: None declared, Miguel A GonzálezGay Grant/research support from: Prof. MA Gonzalez-Gay received grants/ research supports from Abbvie, MSD, Jansen and Roche., Speakers bureau: Consultation fees/participation in company sponsored speaker's bureau from Pfizer, Lilly, Sobi, Celgene, Novartis, Roche and Sanofi., Ricardo Blanco Grant/research support from: Abbvie, MSD, and Roche, Consultant for: Abbvie, Pfizer, Roche, Bristol-Myers, Janssen, Speakers bureau: Abbvie, Pfizer, Roche, Bristol-Myers, Janssen

DOI: 10.1136/annrheumdis-2019-eular.2482

\section{FRI0039 THE LUNG IN AN ENGLISH COHORT OF RHEUMATOID ARTHRITIS PATIENTS - AN OVERVIEW OF DIFFERENT TYPES OF INVOLVEMENT AND TREATMENT}

Ana Catarina Duarte ${ }^{1}$, Joanna Porter ${ }^{2}$, Maria José Leandro ${ }^{3} .{ }^{1}$ Hospital Garcia de Orta, Rheumatology Department, Almada, Portugal; ${ }^{2}$ University College London, Respiratory Medicine, London, United Kingdom; ${ }^{3}$ University College London, Rheumatology Department, London, United Kingdom

Background: Lung disease is described in $5-20 \%$ of patients (pts) with Rheumatoid arthritis (RA) and affects parenchyma, pleura, airways and vasculature; drug-induced pulmonary disease also occurs. It is associated with a higher mortality and identification of safe and effective drugs is essential.

Objectives: Characterize lung involvement in a RA cohort; evaluate rituximab (RTX) effectiveness and safety in RA associated interstitial lung disease (ILD).

Methods: Retrospective analysis of the electronic records from RA cohort followed at University College Hospital. Lung involvement was based on high resolution computed tomography. Demographic data, smoking status, complementary exams at baseline/follow-up and therapies used were analysed. A sub-analysis of pts treated with rituximab (RTX) evaluated response at 12, 24 and 36 months. Declines of $15 \%$ in gas transfer from baseline and/or $10 \%$ in forced vital capacity were recognized.

Results: From 1129 RA pts, 87 (7.7\%) had documented lung involvement. Mean age at last follow-up was $68.3 \pm 12$ years, $74.7 \%$ were female and $85.1 \%$ Caucasian. Median disease duration was 14 (IQR 8-29) years. $54 \%$ of pts had erosive disease. Rheumatoid factor was positive in $88.1 \%$ and anti-citrullinated protein antibodies in $87.8 \% .23$ pts had positive antinuclear antibodies (25 missing data) and 4 anti-Ro, 2 antiScI70 and 2 anti-PL12. Secondary Sjögren's syndrome occurred in $6.9 \%$, cutaneous rheumatoid nodules in $5.7 \%$ and cutaneous vasculitis in $1.1 \%$. $11.5 \%$ and $43.7 \%$ were current and previous smokers, respectively.

Mean interval between onset of articular and pulmonary symptoms was 12.3 years; 2 pts had lung disease as a prior manifestation. Types of lung involvement are shown in table 1.



At last follow-up appointment 22 pts were still on methotrexate (MTX) and 27 had previously received it. MTX-acute pneumonitis occurred in 2 pts, both in the 1st year of treatment.

RTX was used in 26 pts (57.8\%) with ILD (14 nonspecific interstitial pneumonia-NSIP, 8 usual interstitial pneumonia-UIP, 2 organising pneumonia-OP). The mean number of cycles was 4 (range 1-12). Two pts were concomitantly receiving mycophenolate mofetil and 1 azathioprine. RTX treatment outcomes are shown in table 2. 
TABLE 2. - Disease outcomes after treatment with rituximab

\begin{tabular}{|c|c|c|c|c|c|c|c|c|c|c|c|c|}
\hline \multirow{2}{*}{$\begin{array}{l}\text { Time of } \\
\text { revaluation } \\
\text { ILD pattern }\end{array}$} & \multicolumn{3}{|c|}{6 months } & \multicolumn{3}{|c|}{12 months } & \multicolumn{3}{|c|}{24 months } & \multicolumn{3}{|c|}{36 months } \\
\hline & OP & NSIP & UIP & OP & NSIP & UIP & OP & NSIP & UIP & OP & NSIP & UIP \\
\hline TLCO stable/ & $2 / 2$ & $3 / 4$ & & $2 / 2$ & $5 / 5$ & $1 / 3$ & $1 / 1$ & $5 / 5$ & $1 / 1$ & & $3 / 3$ & $2 / 2$ \\
\hline improvement & $100 \%$ & $75 \%$ & & $100 \%$ & $100 \%$ & $33.3 \%$ & $100 \%$ & $100 \%$ & $100 \%$ & & $100 \%$ & $100 \%$ \\
\hline \multirow[t]{2}{*}{ TLCO decline } & & $1 / 4$ & $1 / 1$ & & & $2 / 3$ & & & & & & \\
\hline & & $25 \%$ & $100 \%$ & & & $66.7 \%$ & & & & & & \\
\hline FVC stable/ & $2 / 2$ & $3 / 4$ & & $2 / 2$ & $5 / 5$ & $1 / 3$ & $1 / 1$ & $5 / 5$ & $1 / 1$ & & $4 / 4$ & $1 / 2$ \\
\hline improvement & $100 \%$ & $75 \%$ & & $100 \%$ & $100 \%$ & $33.3 \%$ & $100 \%$ & $100 \%$ & $100 \%$ & & $100 \%$ & $50 \%$ \\
\hline \multirow[t]{2}{*}{ FVC decline } & & $1 / 4$ & $2 / 2$ & & & $2 / 3$ & & & & & & $1 / 2$ \\
\hline & & $25 \%$ & $100 \%$ & & & $66.7 \%$ & & & & & & $50 \%$ \\
\hline HRCT stable/ & & $2 / 2$ & & & $1 / 1$ & $1 / 1$ & & $3 / 3$ & & & $2 / 2$ & \\
\hline improvement & & $100 \%$ & & & $100 \%$ & $100 \%$ & & $100 \%$ & & & $100 \%$ & \\
\hline HRCT & & & & & & & & & $1 / 1$ & & & \\
\hline worsening & & & & & & & & & $100 \%$ & & & \\
\hline
\end{tabular}

Legend: ILD - interstitial lung disease; TLCO - gas transfer; FVC - forced vital capacity; HRCT - high resolution computed tomography; NSIP - non-specific interstitial pneumonia; UIP - usual interstitial pneumonia; OP - organising pneumonia

There were $18(20.7 \%$ ) deaths, 7 of them related to ILD (4 UIP, 3 NSIP) and occurred 8.8 years after ILD diagnosis. Two were due to infection, but none was felt to be directly related to immunosuppressive therapy.

Conclusion: Lung disease occurred in $7.7 \%$ of our cohort, with ILD being the commonest presentation (51.7\%). MTX was widely used in pts with lung disease with only 2 cases of acute pneumonitis. Although the number of ILD pts treated with RTX was small, the drug improved/stabilized the disease in most NSIP and OP pts. UIP is usually progressive, but our data suggest that disease progression might be put on hold with RTX, at least in a subset of pts.

\section{REFERENCE:}

[1] Shaw M, Collins BF, Ho LA, Raghu G. Rheumatoid arthritis-associated lung disease. Eur Respir Rev. 2015 Mar 1;24(135):1-16.

Disclosure of Interests: None declared

DOI: 10.1136/annrheumdis-2019-eular.2237

\section{FRI0040 GENDER DISCREPANCY IN RHEUMATOID ARTHRITIS: PATIENTS' AND PHYSICIANS' PERSPECTIVE}

llaria Duca, Francesca Spinelli, Alessio Altobelli, Bruno Lucchino, Chiara Gioia, Carmelo Pirone, Guido Valesini, Fabrizio Conti, Manuela DI Franco. Policlinico Umberto I, Rheumatology, Department of Internal Medicine and Medical Specialities, Roma, Italy

Background: Rheumatoid Arthritis (RA) is more prevalent among female individuals. Sex and gender differences may influence disease's progression and prognosis. To date, the influence of physicians' gender in the evaluation of RA activity is still largely unknown.

Objectives: aim of the study was to investigate a possible discrepancy in the assessment of disease activity in RA patients evaluated by male and female physicians. Further aim was to compare patient and evaluator perceptions about disease activity and global health status.

Methods: we enrolled consecutive RA patients. Each patient was separately visited by a female and a male rheumatologist of the same age and training level. Tender (TJ) and swollen joints (SJ) count was performed. Global Health (GH), physician's (E-VAS) and patient's (P-VAS) disease activity were reported using a visual analogue scale (VAS 0100). Both examiners were blinded on ESR and CRP. A third rheumatologist assessed disease activity by DAS28-ESR, CDAI and SDAI.

Results: we enrolled 154 patients (122 F, $32 \mathrm{M})$. GH and P-VAS were significantly higher when collected by the female examiner compared to the male one (respectively, $41,1 \pm 24,4$ vs $36,1 \pm 24,3, p<0,0001$ and $41,7 \pm 26,2$ vs $35,3 \pm 25,4 ; p<0,0001$; figure 1 ), as well as DAS28-ESR values $(3,19 \pm 1,5$ vs $2,97 \pm 1,5 ; p<0,0001$; figure 2$)$ but not CDAl and SDAI. On the contrary, male E-VAS was significantly higher compared to female one $(26,8 \pm 27$ vs $20,5 \pm 20,8 ; p<0,0001$; figure 1$)$. GH, P-VAS and DAS28 significantly differ when the analysis was restricted to female patients $(p<0,0001)$; among male patients, only P-VAS was significantly higher when collected by the female examiner $(36,5 \pm 24,7$ vs $30,4 \pm$ $25,4 ; p<0,0001)$. According to the DAS28-ESR cut off, $39,6 \%$ of patients were in remission when evaluated by the female examiner compared to $42,9 \%$ when examined by the male physician; the probability of being judged as having an active disease was not different between the female and the male examiner $(p=n s)$. Overall, the agreement between the female and male evaluation of disease activity was high [Intraclass correlation coefficient (ICC-K) 0,92 for GH; 0,81 for E-VAS; 0,89 for P-VAS; $0,95$ for DAS28-ESR; $p<0,0001]$. When comparing patient and examiner perception of the disease activity, P-VAS values were significantly higher than E-VAS in both female and male examiners $(41,7 \pm 26,2$ vs $20,5 \pm$ 20,$8 ; 35,3 \pm 25,4$ vs $26,8 \pm 27,1 ; p<0,0001$; figure 3 ). The general agreement between male and female examiner and the whole patient population was moderate ( $K \quad 0,65$ and 0,62 , respectively; $p<0,0001$ ), with the lowest agreement between female patients and male examiner ( $K$ o,58; $p<0,0001)$. Female physician had an higher agreement with both male and female patients ( $\mathrm{K} 0,78, \mathrm{~K} 0,62$ respectively; $\mathrm{p}<0,0001$ ).

Conclusion: subjective measure of global health status and disease activity (GH, P-VAS) are generally higher when collected by a female examiner compared to a male one, especially among female patients. This gender discrepancy in subjective measures could influence the evaluation of disease activity indices; however, this does not affect the probability of being defined in remission. Overall, patients have a higher perception of disease activity compared to the health care providers, and the agreement between physician and patients is only moderate, with female patients having the worst perception. Female physician tend to be more in agreement with the patients' judgement of disease activity maybe because of a more emphatic setting established by the female health care provider.

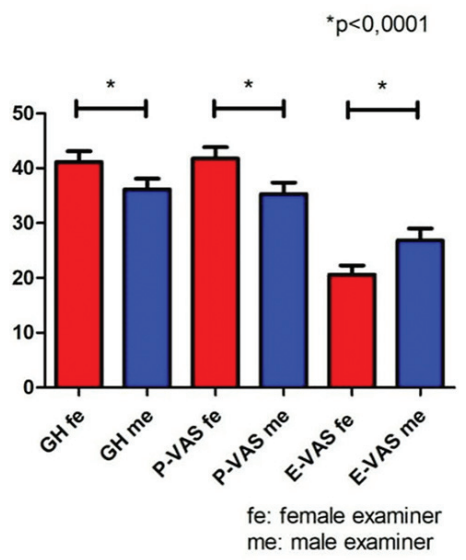

